\title{
Décadrages Décadrages
}

cinéma, à travers champs Cinéma, à travers champs

$13 \mid 2008$

Anna Sanders Films, cinéma et art contemporain

\section{Sonbahar et Yuriev Den : quand environnement rime avec isolement}

Valère Gogniat

\section{(2) OpenEdition}

\section{Journals}

Édition électronique

URL : https://journals.openedition.org/decadrages/539

DOI : $10.4000 /$ decadrages.539

ISSN : 2297-5977

Éditeur

Association Décadrages

Édition imprimée

Date de publication : 10 octobre 2008

Pagination : 115-117

ISBN : 978-2-9700582-8-1

ISSN : 2235-7823

\section{Référence électronique}

Valère Gogniat, "Sonbahar et Yuriev Den : quand environnement rime avec isolement », Décadrages [En ligne], 13 | 2008, mis en ligne le 10 octobre 2009, consulté le 03 avril 2022. URL : http://

journals.openedition.org/decadrages/539; DOI : https://doi.org/10.4000/decadrages.539

Ce document a été généré automatiquement le 3 avril 2022.

( Décadrages 


\title{
Sonbahar et Yuriev Den: quand environnement rime avec isolement
}

\author{
Valère Gogniat
}

1 Nous aimerions revenir sur deux films de la compétition internationale de cette édition du Festival de Locarno, Sonbahar (Automne) du Turc Öscan Alper et Yuriev Den (Le Jour de Yuriev) du Russe Kirill Serebrennikov, qui nous ont semblé remarquables en raison de la manière dont ils mettent en scène les rapports d'un individu avec son environnement.

2 Sonbahar nous présente Yusuf, tout juste sorti de la geôle dans laquelle il vient de passer dix ans suite à son combat pour la démocratie en Turquie. Gravement malade, il retourne dans son petit village natal sur les hauteurs de la mer Noire. Là, il ne retrouve que sa vieille mère souffrante, car son père est mort durant son incarcération. Sa sœur, elle, s'est mariée avec un citadin. La représentation de l'hostilité du milieu dans lequel erre Yusuf nous fait vite comprendre que son retour dans le nord de la Turquie ne s'avère être qu'une autre forme d'emprisonnement.

3 Dans ce film, l'environnement est représenté de différentes manières. Nous avons la nature brute, sauvage et plutôt hostile. Ce sentiment dérangeant de n'être rien face à une nature imposante se retrouve plusieurs fois durant le long métrage. D’abord lors des longs plans sur les montagnes qui encerclent Yusuf. Rocailleuses, démesurées, abruptes, froides, parsemées de nuages, elles ne représentent jamais le sujet d'émerveillement classique mais plutôt une force latente, sourde et féroce. Ensuite dans les réflexions du héros, au bord de la mer Noire, lorsque cette dernière se déchaîne devant lui. Moment particulier, puisque l'un des photogrammes de cette séquence a été sélectionné pour représenter le film durant sa promotion ${ }^{1}$. Il convient de s'arrêter sur cette image puisque sa ressemblance avec le tableau de Caspar David Friedrich «Der Wanderer über dem Nebelmeer» (1817) est saisissante. Un homme, seul face à la nature immense et puissante évoque sans nul doute ce sentiment de petitesse et d'isolement face aux forces naturelles que les grands noms du courant romantiques se plaisaient à dépeindre. Si le film peut se réduire à cette image fixe, alors Yusuf représente sans nul doute l'archétype du romantique solitaire. 
4 Une nature hostile, donc, que l'on retrouvera même sous la forme d'un chien dont on entend systématiquement les aboiements lorsque Yusuf pénètre dans sa maison. Il en va de même dans son village natal, où tout l'esseule. Que ce soit la quasi-impossibilité matérielle de descendre en ville (il n'y a qu'un minibus par jour, et, si on le manque, il faut emprunter l'unique voiture du village), le fait qu'il ne retrouve comme famille que sa vieille mère malade (à qui il ne dira même pas qu'il souffre gravement des poumons) ou encore la prostituée géorgienne qui le quittera au dernier moment, tout son entourage semble condamner Yusuf à rester seul.

5 Yuriev Den met quant à lui en scène Lyuba, une célèbre cantatrice perfectionnée et cultivée qui, avec son fils adolescent, décide de partir en quête de ses racines dans son petit village d'origine. Son fils disparaîtra dans d'étranges circonstances et elle restera seule dans ce village inhospitalier pour le retrouver. A la manière de L'avventura (Michelangelo Antonioni, 1960), Serebrennikov ne s'arrête pas au suspense facile lié à la disparition du fils (on ne saura finalement pas ce qu'il advient exactement de l'adolescent), mais déplace subtilement l'intérêt du spectateur vers l'évolution du personnage de la mère. Ici, l'environnement n'est pas représenté par une nature sauvage, mais bel et bien par une «nature humaine ». C'est donc, et voici le paradoxe le plus fort, un lieu social qui esseule l'héroïne. Le ton est donné dès les premières scènes. Dès son arrivée dans le village, il règne un brouillard si dense que la caméra elle-même perd l'adolescent dans cette brume opaque. Un jeu s'engage entre le spectateur et le fils de Lyuba dans cette atmosphère peu engageante, et c'est ainsi que l'on verra apparaître des villageois, sorte de fantômes égarés. Ce lieu hors du temps se révèle peu à peu et ne révèle que de mauvaises surprises. Des hommes pour la plupart alcooliques (policiers compris), un climat sordide (un meurtre a lieu et personne n'est surpris), des violences fréquentes (chaque soir la femme qui héberge Lyuba reçoit la visite de son ex-mari, qui la bat) ou une température glaciale: autant d'éléments hostiles à l'héroïne. Cet enchevêtrement de situations difficiles développées par le récit contribue ainsi à isoler Lyuba, à poser sa complète inadéquation avec le milieu représenté.

6 De manière plus pragmatique, on peut s'arrêter sur quelques détails. Ainsi les pneus de la voiture de Lyuba disparaissent progressivement, son téléphone portable ne fonctionne que très mal (elle finira par le jeter). De même, son maquillage ou sa coiffure se dégraderont peu à peu au court du film. Ces nombreux détails évoquent l'isolation de Lyuba en tant que "femme du monde " et conduisent à sa dépersonnalisation progressive (le point d'orgue étant le moment où elle se teindra les cheveux en un « rouge intime » désolant, seule teinture disponible dans le village et portée par toutes les femmes).

7 Ces deux films dressent donc avec panache des portraits d'individus aux prises avec un environnement difficile. Ils ont bien quelques faiblesses - on pense par exemple aux clichés repris par Serebrennikov: des hommes pauvres et alcooliques face à des femmes fortes et décidées, une précarité matérielle confrontée à une richesse spirituelle - et ne sont pas toujours aboutis (on notera la difficulté que rencontre Öscan Alper à conclure sur les problèmes politiques de la Turquie ou sur l'immigration clandestine, sujets sur lesquels il ne s'arrête que maladroitement). Mais dans l'ensemble, ces deux fictions nous interpellent et nous dérangent.

Sonbahar (Turquie, Géorgie, 2008, 106')

Réalisation et scénario : Özcan Alper 
Image : Feza Çaldiran

Montage : Thomas Balkenhol

Son : Mohammed Mokhtary

Interprètes : O. Saylak, M. Koboladze,...

Yuriev Den (Russie, 2008, 135')

Réalisation : Kirill Serebrennikov

Scénario : Yuri Arabov

Image : Oleg Lukichev

Montage : Olga Grinshpun

Son : Tilo Feinermann

Interprète : K. Rappoport, S. Sosnovski, R. Shmakov,...

\section{NOTES}

1. Je me réfère ici à l'image utilisée dans la « bible » officielle du festival. 